\title{
New Fungal Anthraquinones ${ }^{1}$
}

\author{
Melvyn Gill* and Peter M. Morgan \\ School of Chemistry, The University of Melbourne, Victoria, 3010 \\ E-mail: melvyn@unimelb.edu.au
}

\begin{abstract}
Dedicated to Prof. D. W. Cameron to mark his retirement and contributions ${ }^{2}$
(received 01 May 01; accepted 19 Dec 01; published on the web 27 Dec 01)
\end{abstract}

\begin{abstract}
The 1-O-methyl ethers $\mathbf{2}$ and $\mathbf{1 1}$ of physcion and emodin, respectively, and emodin anthrone $\mathbf{1 3}$ are isolated for the first time from Basidiomycotina. They are found, along with the parent quinones $\mathbf{1}$ and 10, the tetrahydroanthraquinones (S)-atrochrysone $\mathbf{8}$ and (S)-torosachrysone $\mathbf{9}$, a mixture of atropisomeric flavomannin 6,6'-di-O-methyl ethers $\mathbf{4}$, and the rare anthraquinone fallacinol 7, from among a group of Australian and New Zealand toadstools belonging to the genus Dermocybe.
\end{abstract}

Keywords: Natural products, fungal pigments, anthraquinones, asidiomycotina, Agaricales

\section{Introduction}

We have reported extensively on the chemical constituents of toadstools indigenous to Australia and New Zealand. ${ }^{3,4}$ Many of these secondary metabolites are derived from the polyketide pathway and are either dihydroanthracenones (monomeric ${ }^{5}$ and dimeric ${ }^{6}$ ) or anthraquinones proper. ${ }^{7}$ We describe here the isolation of three compounds: two anthraquinones and an anthrone, that are recorded for the first time from Basidiomycotina. Several new records of other compounds of this class are also recorded here for the first time.

\section{Results and Discussion}

The diminutive fruiting bodies of Dermocybe sp. WAT $22963^{8}$ were collected in the Kinglake and Otway Ranges National Parks, Victoria from under mixed Eucalyptus sp. and Nothofagus cunninghamii, respectively. The sporophore is characterised by red-brown cap skin and bright orange gills. We have reported previously on the major red pigments ${ }^{9}$ and their glycosidic derivatives ${ }^{10}$ from $D$. sp. WAT 22963 and a description of the fungus has been published. ${ }^{9}$ Drawn 
by the complex TLC profile obtained from the organic soluble extractives obtained from this fungus, the minor constituents were examined.

Fresh fungal material was chopped and macerated in ethanol overnight and the extract was evaporated to dryness. The residue was partitioned between water and ethyl acetate and the organic phase was concentrated and purified sequentially by gel permeation and prep. TLC. The most mobile yellow zone $\left(R_{f} 0.80\right)$ obtained by prep. TLC was isolated as orange needles, mp 204-205 ${ }^{\circ} \mathrm{C}$ in a yield of $1.7 \times 10^{-3} \%$ of the fresh weight of the fungus. The molecular formula $\mathrm{C}_{16} \mathrm{H}_{12} \mathrm{O}_{5}$ followed from HR EIMS while UV-visible absorption at $430 \mathrm{~nm}$ and IR absorption at 1681 and $1628 \mathrm{~cm}^{-1}$ suggested an anthraquinone structure. ${ }^{11}$ The ${ }^{1} \mathrm{H}$ NMR spectrum (Table) revealed the presence of $C$-methyl and $O$-methyl groups, four aromatic protons and the protons of two hydrogen bonded phenolic hydroxy groups. These data identified this pigment as physcion $\mathbf{1}$, a conclusion that was confirmed by direct comparison with an authentic sample. ${ }^{12}$ Physcion $\mathbf{1}$ is widespread but only as a trace constituent in Cortinarius and Dermocybe species. ${ }^{7}$

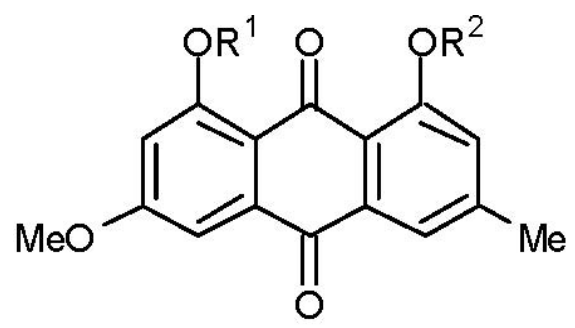

$$
\begin{array}{ll}
1 & R^{1}=R^{2}=H \\
2 & R^{1}=H, R^{2}=M e \\
3 R^{1}=M e, R^{2}=H
\end{array}
$$

A second yellow zone $\left(R_{f} 0.73\right)$ gave orange needles, mp $191-192{ }^{\circ} \mathrm{C}$ in a yield of $8 \times 10^{3} \%$ of the fresh weight of the fungus. The EIMS shows a molecular ion at $m / z 298\left(\mathrm{C}_{17} \mathrm{H}_{14} \mathrm{O}_{5}\right)$ that corresponds to the elements $\mathrm{CH}_{2}$ more than physcion 1. The $\mathrm{H}$ NMR spectrum confirms the presence of two methoxy groups ( $\delta 3.91$ and 4.06), one $C$-methyl group ( $\delta 2.51)$, four aromatic protons $(\delta 6.70,7.15,7.31$ and 7.77$)$ and one phenolic hydroxy group ( $\delta 13.30)$. The aromatic protons at $\delta 6.70$ and 7.31 aremeta-coupled $(J=2.45 \mathrm{~Hz})$, while the signals at $\delta 7.15$ and 7.77 are broadened by both meta-and allylic coupling. In the absence of further evidence these data do not differentate between the 1-and the 8-O-methyl ethers $\mathbf{2}$ and $\mathbf{3}$, respectively, of physcion $\mathbf{1}$. The ether $\mathbf{2}$ has been isolated from plant tissue cultures, ${ }^{13}$ while $\mathbf{3}$ is a metabolite of plants and microorganisms. ${ }^{14}$ Comparison of the physical and spectroscopic data for the quinone from Dermocybe sp. WAT 22963 with those published for synthetic physcion 1-O-methyl ether $\mathbf{2}^{15}$ and for physcion 8-O-methyl ether $\mathbf{3}^{14}$ established its identity with the former (Table). This is the first time that physcion 1-O-methyl ether $\mathbf{2}$ has been isolated from Basidiomycotina. 


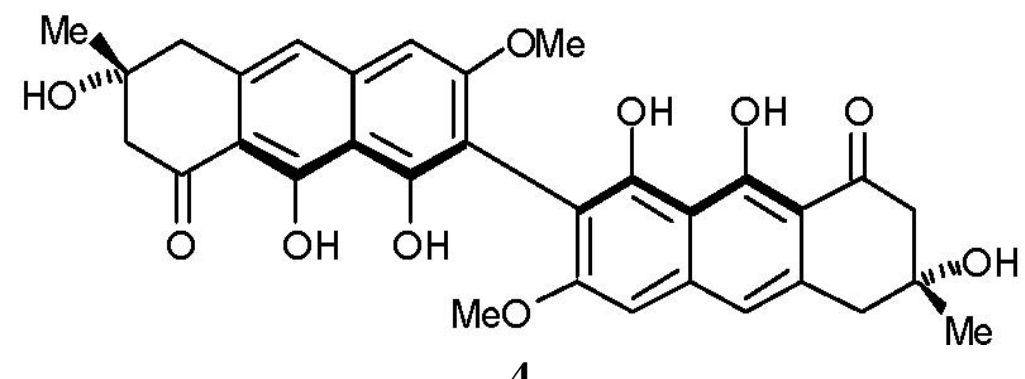

The least mobile zone $\left(R_{f} 0.18\right)$ from prep. TLC gave flavomannin 6,6'-di-O-methyl ether 4 as a yellow-green powder, mp $201-204{ }^{\circ} \mathrm{C}$, in a yield of $6.7 \times 10^{-2} \%$ of the fresh weight of the fungus. A molecular ion at $\mathrm{m} / \mathrm{z} 574$ in the EIMS was consistent with the molecular formula $\mathrm{C}_{32} \mathrm{H}_{30} \mathrm{O}_{10}$ while the ${ }^{1} \mathrm{H}$ NMR spectrum, which shows signals from only one half of the number of protons in the molecule, is characteristic of a 7,7'-linked dihydroanthracenone dimer. ${ }^{7}$ Flavomannins and their ethers, such as $\mathbf{4}$, are known from Cortinarius and Dermocybe in various stereochemical forms. ${ }^{7}$ The presence in each half of the molecule of (at least) one stereogenic centre (C-3) coupled with atropisomerism about the hindered biaryl axis introduces considerable stereochemical complexity into these molecules that has only recently been addressed. ${ }^{16}$ The absolute configuration at the biaryl axis in compounds of the flavomannin series is conveniently determined from the CD spectrum. Thus, the signs of the strong bisignate Cotton effects close to $275 \mathrm{~nm}$ can be related directly to the stereochemistry at the axis. ${ }^{17}$ The CD spectrum of flavomannin 6,6'-di-O-methyl ether 4 from $D$. sp. WAT 22963 shows a negative Cotton effect $(\Delta \varepsilon-9.0)$ at $293 \mathrm{~nm}$ and a positive Cotton effect $(\Delta \varepsilon+17.1)$ at $271 \mathrm{~nm}$ consistent with $(M)$ chirality at the axis. ${ }^{16,17}$ The stereochemistry of the C-3 and C-3' chiral centres in 4 was determined by adding, in turn, authentic samples of the $\left(3 R, 3^{\prime} R, M\right)$ - and (3S, $\left.3^{\prime} S, M\right)$ stereoisomers of $\mathbf{4}$, from Cortinarius citrinus and C. pseudosulphureus, respectively, ${ }^{18}$ to a sample of 4 in deuteriochloroform and recording the ${ }^{1} \mathrm{H}$ NMR spectrum. The ${ }^{1} \mathrm{H}$ NMR spectrum of the solution containing 4 together with the $\left(3 R, 3^{\prime} R, M\right)$-isomer showed a single set of resonances with no discernible broadening or doubling of the C-6/6' methoxy or C-8/8' hydroxy resonances. In contrast, the ${ }^{1} \mathrm{H}$ NMR spectrum of the solution containing 4 together with the $\left(3 S, 3^{\prime} S, M\right)$-isomer showed distinct broadening of the signal at $\delta 3.83$ (C-6/6'-OMe) and clear doubling of the signal at $\delta 9.98\left(\mathrm{C}-8 / 8^{\prime}-\mathrm{OH}\right)$. These results establish unequivocally that the flavomannin 6,6'-di-O-methyl ether isolated from $D$. sp. WAT 22963 is predominantly the $\left(3 R, 3 R^{\prime}, 3 M\right)$-stereoisomer shown in formula 4 .

Having established that the flavomannin derivative $\mathbf{4}$ was not present in $D$. sp. WAT 22963 in admixture with any of its diastereoisomers, we considered next its enantiomeric purity. $\left(3 R, 3^{\prime} R, M\right)$-Flavomannin 6,6'-di-O-methyl ether 4 was earlier isolated by us from the Australian Dermocybe sp. WAT 20880. ${ }^{16}$ That sample exhibited extrema in the CD spectrum at $287 \mathrm{~nm}$ $(\Delta \varepsilon-68.3)$ and $265 \mathrm{~nm}(\Delta \varepsilon+72.4)$, which suggests that the sample described here is an anisochiral mixture ${ }^{19}$ of $\mathbf{4}$ with its (3S,3'S,P)-enantiomer ent-4 in a ratio of no more than 62:38 (24\% ee) in favour of the former. 
<smiles>[R]Cc1cc(OC)c2c(c1)C(=O)c1c(O)c(OC)cc(O)c1C2=O</smiles>

$5 \mathrm{R}=\mathrm{H}$

$6 \mathrm{R}=\mathrm{OH}$<smiles>O=C1c2cc(O)cc(O)c2C(=O)c2c(O)cc(CO)cc21</smiles>

7

Dermocybe sp. WAT 26644 was collected from under Nothofagus menziesii in the Caitlins River Park, South Otago, New Zealand in May 1995. The fruiting bodies very closely resemble those of Dermocybe sp. WAT 22963 described previously, ${ }^{9}$ and a taxonomic relationship between the two species was supported by preliminary TLC analysis of the ethanolic extracts of the New Zealand taxon. The TLC reveals the presence in D. sp. WAT 26644 of five pigments with the same chromatographic properties as compounds previously isolated from $D$. sp. WAT 22963. ${ }^{9,10}$ The extracts of $D$. sp. WAT 26644 were subsequently partitioned between ethyl acetate and water and the organic phase was separated and the contents purified by gel permeation and prep. TLC. Physcion $\mathbf{1}$, its methyl ether $\mathbf{2}$, and the xanthorin derivatives $\mathbf{5}$ and $\mathbf{6}$ , previously reported from $D$. sp. WAT 22963, were identified by direct comparison with authentic materials. ${ }^{9}$ A yellow zone ( $R f$ 0.25) that is not present in the TLC of $D$. sp. WAT 22963, was isolated as orange needles, mp 242-244 ${ }^{\circ} \mathrm{C}$, in a yield of $1.0 \times 10^{-2 \%}$. The molecular formula $\mathrm{C}_{16} \mathrm{H}_{12} \mathrm{O}_{6}$ was determined by HR EIMS and the pigment was identified as fallacinol 7 from the IR ( $v 1630$ and $1671 \mathrm{~cm}^{-1}$ ) and UV- visible data $\left(\lambda 412 \mathrm{~nm}\right.$ ) and from the ${ }^{1} \mathrm{H}$ NMR spectrum. Finally, comparison of all of the spectroscopic data for the yellow pigment from $D$. sp. WAT 26644 with the literature data for fallacinol 7 confirmed the identity of the pigment. $^{20}$ Fallacinol 7 has been isolated previously only from Dermocybe cinnabarina ${ }^{20}$ but has been detected chromatographically in extracts of several other Cortinarius species. ${ }^{21}$ Prior to our recent discovery of $w$-hydroxyxanthorin 1 -O-methyl ether $\mathbf{6},{ }^{9}$ fallacinol 7 was the only $w$ substituted anthraquinone known from Basidiomycetes. 


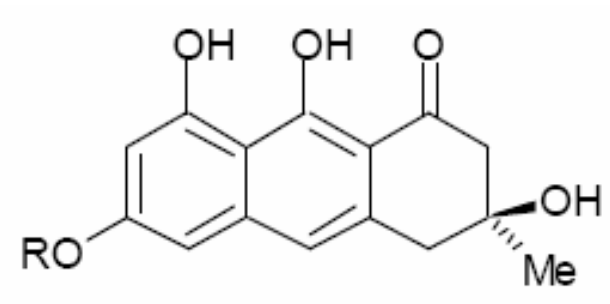

$8 \mathrm{R}=\mathrm{H}$

$9 \mathrm{R}=\mathrm{Me}$

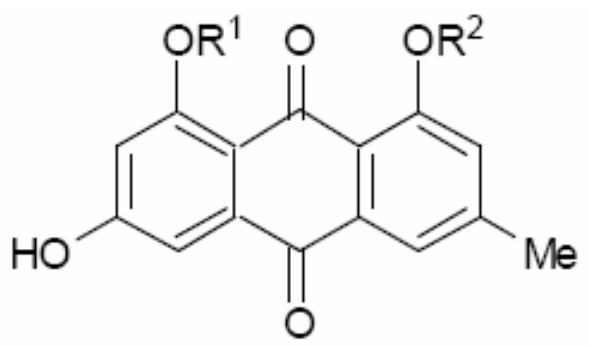

$10 \mathrm{R}^{1}=\mathrm{R}^{2}=\mathrm{H}$

$11 \mathrm{R}^{1}=\mathrm{H}, \mathrm{R}^{2}=\mathrm{Me}$

$12 \mathrm{R}^{1}=\mathrm{Me}, \mathrm{R}^{2}=\mathrm{H}$

The green-yellow zone $\left(R_{f} 0.18\right), \mathrm{C}_{32} \mathrm{H}_{30} \mathrm{O}_{10}$, from the New Zealand Dermocybe sp. WAT 26644 was identified as a mixture of $\left(3 R, 3 R^{\prime}, M\right)$-flavomannin 6,6'-di-O-methyl ether 4 and its $\left(3 R, 3 R^{\prime}, P\right.$ )-atropisomer (not shown) from the ${ }^{1} \mathrm{H}$ NMR and CD spectra. Thus, the ${ }^{1} \mathrm{H}$ NMR spectrum showed distinct doubling of the signals due to the C-6/6' methoxy groups ( $\delta 3.82$ and 3.84) and the C-8/8' hydroxy groups ( $\delta 9.98$ and 10.14) consistent with the presence of two diastereoisomers. That these are atropisomers rather than epimers is apparent from the CD spectrum, which shows no significant net absorption in the vicinity of $275 \mathrm{~nm}$. Weak absorption at shorter wavelength (Experimental) accords with the CD spectrum of $(R)$-torosachrysone ent-9 and supports the $\left(3 R, 3^{\prime} R\right)$ central chirality in both of the flavomannin isomers present in $D$. sp. WAT 26644. An atropisomeric mixture of flavomannin 6,6'-di-O-methyl ethers of undefined absolute configuration has been isolated before from Tricholoma auratium .

It is clear from the chemical analysis of the New Zealand taxon $D$. sp. WAT 26644 that it must be very close taxonomically to the Australian taxon $D$. sp. WAT 22963. The only differences in the pigment composition of the two species being (i) the presence in the former of fallacinol 7 and (ii) the stereochemical constitution of the flavomannin 6,6'-di-O-methyl ether that is present in each species.

Fruit bodies of Dermocybe sp. WAT 26813 were collected in leaf litter under Nothofagus cunninghamii at Mait's Rest, Otway Ranges National Park, Victoria. They have a pale orangebrown cap and a yellow-green stipe. TLC analysis of the ethanolic extract revealed the presence of two green pigments $\left(R_{f} 0.24\right.$ and 0.35$)$ and three yellow pigments ( $R f 0.42,0.48$ and 0.65 ). The residue remaining after evaporation of the solvent was partitioned between ethyl acetate and water and the organic phase was purified by prep. TLC. Green zones $\left(R_{f} 0.24\right.$ and 0.35$)$ were identified as (S)-atrochrysone $\mathbf{8}$ and (S)-torosachrysone $\mathbf{9}$, respectively, from their physical, chiroptical and spectroscopic properties and by direct comparison with authentic materials. ${ }^{22}(S)-$ Atrochrysone 8 has been reported previously from several European Dermocybe species ${ }^{7}$ but only once before from an Australian member of the genus. ${ }^{22}(S)$-Torosachrysone $\mathbf{9}$, on the other hand, is common among Australian dermocybes ${ }^{4}$ but has yet to be recorded from members of the genus indigenous to other parts of the World.

The most mobile yellow pigment $\left(R_{f} 0.65\right)$ from $D$. sp. WAT 26813 was identified as emodin 
10 (8.3 x 10 $\%$ ), a common natural product. ${ }^{11,13,14}$ from the spectroscopic data and by comparison with a commercial sample. The more polar yellow zones ( $R_{f} 0.48$ and 0.42 ) contained metabolites that have not previously been recorded from Dermocybe or Cortinarius. The least polar of the two was isolated as orange needles, mp $265-267^{\circ} \mathrm{C}$, in a yield of $3.3 \times 10^{-}$ ${ }^{3} \%$ of the fresh weight of the fungus. The formula $\mathrm{C}_{16} \mathrm{H}_{12} \mathrm{O}_{5}$ followed from HR EIMS of the molecular ion at $\mathrm{m} / \mathrm{z} 284$, while the presence of an emodin chromophore was indicated by a long wavelength absorption at $429 \mathrm{~nm}$ [ $\lambda$ (emodin): $436 \mathrm{~nm}$ ] in the UV-visible spectrum. The IR spectrum implied the presence of free and hydrogen bonded quinonoid carbonyl groups with absorptions at 1663 and $1625 \mathrm{~cm}^{-1}$, respectively. The ${ }^{1} \mathrm{H}$ NMR spectrum (Table) contains signals characteristic of aromatic $C$-and $O$-methyl groups, two pairs of meta-coupled aromatic protons and a hydrogen bonded phenolic hydroxy group. These data are accommodated by both the 1and the 8-O-methyl ether structures 11 and 12, respectively, of emodin 10. Both ethers are known: the former was isolated recently from the 'aspen fungus' Phialophora alba, which grows on Populus tremuloides, ${ }^{23}$ and from cultures of Fusarium aquaeductuum. ${ }^{24}$ Emodin 8-O-methyl ether $\mathbf{1 2}$ is a widespread natural product. ${ }^{14}$ The methyl ethers $\mathbf{1 1}$ and $\mathbf{1 2}$ have been synthesised by Cameron $^{25}$ and Brassard, ${ }^{26}$ respectively. Comparison of the ${ }^{1} \mathrm{H}$ NMR data of the pigment from $D$. sp. WAT 26813 with those reported for the synthetic ethers (Table) reveals that it corresponded more closely to emodin 1-O-methyl ether $\mathbf{1 1}$ than it did to the isomer $\mathbf{1 2}$. The identity of the quinone from Dermocybe sp. WAT 26813 with the 1-O-methyl ether 11 of emodin was confirmed by direct comparison with a synthetic sample. ${ }^{25}$ Both the natural and synthetic specimens of $\mathbf{1 1}$ had the same mp and a mixed mp showed no depression. Furthermore, a single set of proton resonances was observed in the ${ }^{1} \mathrm{H}$ NMR spectrum when the natural and synthetic materials were mixed together. Emodin 1-O-methyl ether $\mathbf{1 1}$ is an inhibitor of the growth of the parasitic fungus Phellinus tremulae at a concentration of $1 \mathrm{mg} \mathrm{mL}^{-1} \cdot{ }^{23}$ This is the first report of the isolation of emodin 1-O-methyl ether 11 from the Basidiomycotina.

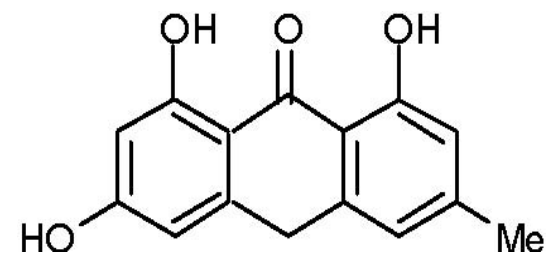

13

The least mobile yellow zone $\left(R_{f} 0.42\right)$ gave yellow-green plates, mp 250-254 ${ }^{\circ} \mathrm{C}$ (decomp.) in a yield of $4.2 \times 10^{-3} \%$. The EIMS contains a molecular ion at $\mathrm{m} / \mathrm{z} 256$ while the FAB MS exhibits $[\mathrm{M}+\mathrm{Na}]^{+}$and $[\mathrm{M}+1]^{+}$ions at 279 and 257, respectively. The HR EIMS established the molecular formula $\mathrm{C}_{15} \mathrm{H}_{12} \mathrm{O}_{4}$, which corresponds to two hydrogen atoms more and one oxygen atom less than the molecular formula for emodin 10. In the ${ }^{1} \mathrm{H}$ NMR spectrum (see Experimental) this pigment gives rise to singlets due to two hydrogen bonded phenolic hydroxy groups, a three proton singlet corresponding to an aromatic methyl group and a two proton singlet at $\delta 4.31$. In the aromatic proton region two pairs of meta-disposed protons reveal a 
typical emodin substitution pattern. Consideration of the molecular formula and the two proton singlet at $\delta 4.31$ in the ${ }^{1} \mathrm{H}$ NMR spectrum led to the emodin anthrone structure $\mathbf{1 3}$ for this constituent of $D$. sp. WAT 26813. Comparison of the physical and spectroscopic data recorded here with those published for emodin anthrone ${ }^{27}$ confirmed the identity of the pigment. This is the first report of emodin anthrone $\mathbf{1 3}$ from Basidiomycotina.

Table 1. H NMR data of the anthraquinones 1, 2, 3, 11 and $12\left(\mathrm{CDCl}_{3}, 400 \mathrm{MHz}\right)$

\begin{tabular}{|c|c|c|c|c|c|c|c|}
\hline H -2 & 7.09 br s & $7.15 \mathrm{br} \mathrm{s}$ & $7.14 \mathrm{brs}$ & 7.01 br s & 7.16 br s & 7.16 br s & 7.10 br s \\
\hline 3-Me & $2.45 \mathrm{~s}$ & $2.51 \mathrm{~s}$ & $2.50 \mathrm{~s}$ & $2.38 \mathrm{~s}$ & $2.51 \mathrm{~s}$ & $2.51 \mathrm{~s}$ & 2.38 \\
\hline H -4 & 7.64 br s & 7.77 br s & 7.74 br s & $7.49 \mathrm{br} \mathrm{s}$ & 7.77 br s & 7.76 br s & 7.40 br s \\
\hline H -5d & $7.38 \mathrm{~d}$ & $7.31 \mathrm{~d}$ & $7.29 \mathrm{~d}$ & $7.36 \mathrm{~d}$ & $7.21 \mathrm{~d}$ & $7.22 \mathrm{~d}$ & $7.21 \mathrm{~d}$ \\
\hline H -7d & $6.70 \mathrm{~d}$ & $6.70 \mathrm{~d}$ & $6.69 \mathrm{~d}$ & $6.69 \mathrm{~d}$ & $6.67 \mathrm{~d}$ & 6.67 & $6.85 \mathrm{~d}$ \\
\hline $1-\mathrm{OH}$ & $12.13 \mathrm{~s}$ & - & - & $11.99 \mathrm{~s}$ & - & - & - \\
\hline 6-OH & - & - & - & - & - & - & - \\
\hline $8-\mathrm{OH}$ & $12.33 \mathrm{~s}$ & $13.30 \mathrm{~s}$ & $13.33 \mathrm{~s}$ & - & $13.27 \mathrm{~s}$ & $13.28 \mathrm{~s}$ & - \\
\hline 1-OMe & - & $4.06 \mathrm{~s}$ & $4.06 \mathrm{~s}$ & - & $4.06 \mathrm{~s}$ & $4.06 \mathrm{~s}$ & - \\
\hline 6-OMe & $3.94 \mathrm{~s}$ & $3.91 \mathrm{~s}$ & $3.93 \mathrm{~s}$ & $3.96 \mathrm{~s}$ & - & - & - \\
\hline 8-OMe & - & & & $3.92 \mathrm{~s}$ & - & - & $3.92 \mathrm{~s}$ \\
\hline
\end{tabular}

${ }^{\text {a) }}$ From Dermocybe sp WAT 22963.

b) Authentic sample, see reference 25.

c) Recorded in $d 6-\mathrm{DMSO}$ at $100 \mathrm{MHz}$.

d) $\mathrm{JH} 5-\mathrm{H} 7=2.4-2.6 \mathrm{H} \mathrm{z}$.

In summary, from two indigenous Australian and one indigenous New Zealand toadstool the 1-O-methyl ethers $\mathbf{2}$ and $\mathbf{1 1}$ of emodin and physcion, respectively, and emodin anthrone $\mathbf{1 3}$ are reported for the first time from Basidiomycotina. In addition, flavomannin 6,6'-di-O-methyl ether 4 is reported in different degrees of stereochemical purity from some closely related members of this group of fungi and the occurrence of the rare (S)-atrochrysone $\mathbf{8}$ and (S)-torosachrysone $\mathbf{9}$ is extended to several new indigenous taxa.

\section{Experimental Section}

General Procedures. Mps: Kofler hotstage apparatus; uncorr; Optical rotation: Perkin-Elmer 241 polarimeter; CD: AVIV 62DS spectrometer; Prep. TLC: Merck Kieselgel GF $_{254}$; TLC: Macherey-Nagel SIL G-25; toluene/ $\mathrm{HCO}_{2} \mathrm{Et} / \mathrm{HCO}_{2} \mathrm{H}$ (50:49:1); CC: Sephadex LH-20 
(Pharmacia); NMR: JEOL JNM GX-400 spectrometer $\left({ }^{1} \mathrm{H}\right.$ at $399.65 \mathrm{MHz}$ and ${ }^{13} \mathrm{C}$ at 100.4 MHz); IR: Perkin-Elmer 983G grating spectrophotometer; UV-visible: Varian SuperScan 3 spectrophotometer using $10 \mathrm{~mm}$ quartz cells and EtOH as the solvent; EIMS: VG Micromass 7070F and JEOL JMS-AX505HF spectrometers (70 eV).

\section{Plant material}

Fungi were collected from the following locations (lyophilised specimens of each species are lodged in the herbarium of the Royal Botanic Garden, Edinburgh, under the accession numbers quoted): Dermocybe sp. WAT 22963: Kinglake (1993) and Otway Ranges (1995) National Parks, Victoria, Australia from under Nothofagus cunninghamii. D. sp. WAT 26644: Catlin's River Park, South Otago, New Zealand, from under Nothofagus menziesii (1995). D. sp. WAT 26813: Mait's Rest, Otway Ranges National Park, Victoria, from under Nothofagus cunninghamii.

\section{Extraction and isolation}

\section{From Dermocybe sp. WAT 22963}

Fresh fruiting bodies (6 g) were finely chopped and soaked overnight in EtOH (300 mL) at room temperature. The solid material was filtered off and the solvent was evaporated. The greenbrown residue was partitioned between EtOAc $(150 \mathrm{~mL})$ and $\mathrm{H}_{2} \mathrm{O}(150 \mathrm{~mL})$. A second collection (24 g), from Kinglake National Park, was extracted in the same way.

The organic phase was separated, dried $\left(\mathrm{Na}_{2} \mathrm{SO}_{4}\right)$ and evaporated to dryness to afford a greenbrown residue (40 mg) which was purified by PLC using toluene/ $\mathrm{HCO}_{2} \mathrm{Et} / \mathrm{HCO}_{2} \mathrm{H}(50: 49: 1)$ as eluant to give the following compounds: physcion $1\left(0.5 \mathrm{mg}, 1.7 \times 10^{-3} \% \mathrm{fr}\right.$. wt.) as orange needles (EtOAc-PE); mp 204-205 ${ }^{\circ} \mathrm{C}$ (lit. ${ }^{11} 207-209{ }^{\circ} \mathrm{C}$ ); TLC: $R_{f} 0.80$; IR $v(\mathrm{KBr}) \mathrm{cm}^{-1}$ : 3505, 1681, 1628; UV-Vis $\lambda$ (EtOH) nm (log $\varepsilon$ ): 258 sh (4.28), 268 (4.34), 286 (4.33), 430 (4.14); NMR: Table; EIMS m/z (rel. int.): $284\left(\mathrm{M}^{+}, 100\right)$; physcion 1-O-methyl ether 2 (2.4 mg, 8.0 x 10 $\%$ fr. wt.) as orange needles $\left(\mathrm{CHCl}_{3}-\mathrm{PE}\right)$; mp $191-192{ }^{\circ} \mathrm{C}$ (lit. ${ }^{13} 188-191{ }^{\circ} \mathrm{C}$ ); TLC: Rf 0.73; HR EIMS (rel. int.): found $298.0821[\mathrm{M}]^{+}(100 \%)$, requires $\mathrm{C}_{17} \mathrm{H}_{14} \mathrm{O}_{5} 298.0845$; IR $v(\mathrm{KBr}) \mathrm{cm}^{-1}$ : 3420, 1690, 1625; UV-Vis $\lambda(\mathrm{EtOH}) \mathrm{nm}$ (log $\varepsilon$ ): 222 sh (3.98), 269 (4.60), 320 (3.03), 429 (3.86); NMR: Table 1; EIMS m/z (rel. int.): 298 (M+1 100), 280 (39), 269 (20), 252 (44), 149 (75); xanthorin 1-O-methyl ether 5 (2.7 mg, 9.0 x 10 ${ }^{-3} \%$ fr. wt.) as red needles $\left(\mathrm{CHCl}_{3}\right)$; mp 204-205 ${ }^{\circ} \mathrm{C}$ (lit. ${ }^{9}$ 205-209 ${ }^{\circ} \mathrm{C}$ ); TLC: Rf 0.55; IR $\vee(\mathrm{KBr}) \mathrm{cm}^{-1}$; 3434, 1660, 1624 ; UV-Vis $\lambda$ $(\mathrm{EtOH}) \mathrm{nm}$ ( $\log \varepsilon$ ): 221 (2.91), 230 (2.84), 236 (2.83), 256 (2.89), 294 (2.32), 469 (2.18), 495 (2.26), 530 (2.06); ${ }^{1} \mathrm{H}$ NMR $\delta 2.53$ (3H, s, 3-Me), 3.99 (3H, s, 6-OMe), 4.07 (3H, s, 1-OMe), 6.71 (1H, s, H-7), 7.17 (1H, br s, H-2), 7.86 (1H, br s, H-4), 13.43 (1H, s, 5-OH), 13.98 (1H, s, 8$\mathrm{OH}$ ); EIMS m/z (rel. int.): 314 ( $\left.\mathrm{M}^{+}, 100\right), 296$ (53), 253 (22); $\omega$-hydroxyxanthorin 1-O-methyl ether 6 (1.5 mg, $5.0 \times 10^{-3} \%$ fr. wt.) as red needles $\left(\mathrm{CHCl}_{3}\right)$; mp 220-222 ${ }^{\circ} \mathrm{C}$ (lit. ${ }^{9} 220-223{ }^{\circ} \mathrm{C}$ ); TLC: $R f$ 0.20; IR $\vee(\mathrm{KBr}) \mathrm{cm}^{-1}$ : 3432, 1650, 1618, 1583; UV-Vis $\lambda(\mathrm{EtOH}) \mathrm{nm}(\log \varepsilon): 220$ (2.95), 230 (2.86), 236 (2.87), 255 (3.00), 294 (2.45), 465 (2.32), 495 (2.34), 530 (2.15); ${ }^{1} \mathrm{H}$ NMR $\left(\mathrm{CDCl}_{3}\right) \delta 3.99$ (3H, s, 6-OMe), 4.10 (3H, s, 1-OMe), $4.89\left(2 \mathrm{H}, \mathrm{s}, 3-\mathrm{CH}_{2} \mathrm{OH}\right), 6.72(1 \mathrm{H}, \mathrm{s}$, H-7), 7.51 (1H, br s, H-2), 7.98 (1H, br s, H-4), 13.41 (1H, s, 5-OH), 13.96 (1H, s, 8-OH); EIMS 
m/z (rel. int.): 330 ( $\left.\mathrm{M}^{+}, 74\right), 312$ (46), 284 (30), 56 (100); and flavomannin 6,6'-di-O-methyl ether 4 (20.1 mg, $6.7 \times 10^{-2} \%$ fr. wt.) as a bright yellow-green powder (EtOAc-PE); mp 201-204

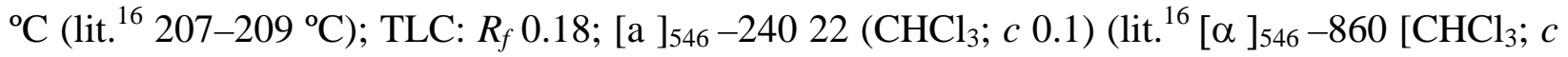
0.02]); IR $\vee(\mathrm{KBr}) \mathrm{cm}^{-1}: 3384,1627,1550$; UV-Vis $\lambda(\mathrm{EtOH}) \mathrm{nm}$ (log $\varepsilon$ ): 235 (4.51), 261 (4.55), 270 (4.50), 285 (4.51), 320 (3.98), 415 (3.20); CD $\lambda \mathrm{nm}(\Delta \varepsilon) 440$ (+3.3), 400 (-3.0), 323 (-0.4), 293 (-9.0), 271 (+17.1), $242(-2.8), 229(-1.0), 216(-2.9) \mathrm{nm} ;{ }^{1} \mathrm{H}$ NMR $\left(\mathrm{CDCl}_{3}\right) \delta 1.44$ (6H, s, 3/3'-Me), 2.83 (4H, br s, H-2/2'), 3.06 (4H, br s, H-4/4'), 3.84 (6H, s, 6/6'-OMe), 6.67 (2H, s, H-5/5'), 6.93 (2H, s, H-10/10'), 9.98 (2H, s, 8/8'-OH), 16.15 (2H, s, 9/9'-OH); EIMS m/z (rel. int.): 574 (M+1, 32), 538 (29), 507 (100), 254 (17).

\section{From Dermocybe sp. WAT 26644}

Fresh toadstools $(7 \mathrm{~g})$ were chopped and soaked overnight in EtOH $(100 \mathrm{~mL})$ at room temperature. Evaporation of the solvent gave a green-brown residue that was partitioned between EtOAc $(50 \mathrm{~mL})$ and $\mathrm{H}_{2} \mathrm{O}(50 \mathrm{~mL})$. The organic phase was dried $\left(\mathrm{Na}_{2} \mathrm{SO}_{4}\right)$ and evaporated to afford a yellow-brown residue $(20 \mathrm{mg}$ ) that was separated by PLC to give six pure compounds: physcion 1 (0.5 mg, $7.1 \times 10^{-3} \%$ fr. wt.); physcion 1-O-methyl ether $2\left(0.3 \mathrm{mg}, 4.3 \times 10^{-30} \mathrm{fr}\right.$. wt.); xanthorin 1-O-methyl ether 5 (2.1 mg, $3.0 \times 10^{-2} \%$ fr. wt.); $\omega$-hydroxyxanthorin 1-O-methyl ether 6 (1.3 mg, $1.9 \times 10^{-2} \% \mathrm{fr}$. wt.), all identical with materials described previously; fallacinol 7 (0.7 mg, $1.0 \times 10^{-2} \%$ fr. wt.) as orange needles (EtOAc-PE); mp $242-244{ }^{\circ} \mathrm{C}$ (lit. ${ }^{20} 245-247$ $\left.{ }^{\circ} \mathrm{C}\right)$; TLC: $R f$ 0.25; IR $v(\mathrm{KBr}) \mathrm{cm}^{-1}: 3452,1671,1630,1624$; UV-Vis $\lambda$ (EtOH) nm (log $\varepsilon$ ): 221 (4.22), 261 (4.21), 289 sh (3.98), 421 (3.60); UV-Vis $\lambda$ (EtOH + 1\% NaOH) nm (log $\varepsilon$ ): 512 (3.45); ${ }^{1} \mathrm{H} \mathrm{NMR}\left(\mathrm{CDCl}_{3}\right) \delta 3.95$ (3H, s, 6-OMe), $4.82(2 \mathrm{H}, \mathrm{s}, 3-\mathrm{CH} 2 \mathrm{OH}), 6.71(1 \mathrm{H}, \mathrm{d}, J=2.2$, H-7), 7.30 (1H, br s, H-2), 7.40 (1H, d, J = 2.2, H-5), 7.79 (1H, br s, H-4), 12.19 and 12.29 (2 x 1H, each s, 1/8-OH); EIMS m/z (rel. int.): 300 (M+, 100), 271 (43), 149 (14), 98 (21), 57 (66); and flavomannin 6,6'-di- $O$-methyl ether $4+$ atrop-4 (5.6 mg, $8.0 \times 10^{-2} \%$ fr. wt.) as an orange powder (EtOAc); mp 287-289 ${ }^{\circ} \mathrm{C}$; TLC: $R_{f} 0.18$; [a ] ${ }_{546}^{13}-412\left(\mathrm{CHCl}_{3} ;\right.$ c 0.1); IR $v(\mathrm{KBr}) \mathrm{cm}^{-1}$ : 3384, 1627, 1550; UV-Vis $\lambda$ (EtOH) nm (log $\varepsilon$ ): 235 (4.51), 261 (4.55), 270 (4.50), 285 (4.51), 320 (3.98), 415 (3.20); CD $\lambda(\mathrm{EtOH}) \mathrm{nm}(\Delta \varepsilon) 273(-0.9), 226(+2.4), 211(-4.1) ;{ }^{1} \mathrm{H}$ NMR $\delta$ 1.44 (12H, s, 3/3'-Me), 2.83 (8H, br s, H-2/2'), 3.06 (8H, br s, H-4/4'), 3.82 (6H, s, 6/6'-OMe), 3.84 (6H, s, 6/6'-OMe), 6.67 (4H, s, H-5/5'), 6.93 (4H, s, H-10/10'), 9.98 (2H, s, 8/8'-OH), 10.14 (2H, s, 8/8'-OH), 16.15 (4H, br s, 9/9'-OH); EIMS m/z (rel. int.): 574 (M+1 32), 538 (29), 507 (100).

\section{From Dermocybe sp. WAT 26813}

Fresh fruiting bodies (12 g) were finely chopped and soaked overnight in EtOH (300 mL) at room temperature. Solid material was filtered off and the solvent was evaporated to dryness and the residue was partitioned between EtOAc $(150 \mathrm{~mL})$ and $\mathrm{H}_{2} \mathrm{O}(150 \mathrm{~mL})$. The organic phase was dried $\left(\mathrm{Na}_{2} \mathrm{SO}_{4}\right)$ and evaporated to give a dark green-brown residue $(40 \mathrm{mg})$. The residue was purified by PLC using toluene/ $\mathrm{HCO}_{2} \mathrm{Et} / \mathrm{HCO}_{2} \mathrm{H}$ (50:49:1) and $\mathrm{CHCl}_{3} / \mathrm{EtOH} / \mathrm{HCO}_{2} \mathrm{H}$ (100:20:1) as the eluant. Five compounds were isolated in pure form: (S)-torosachrysone 9 (4.6 mg, $3.8 \mathrm{x}$ $10^{-2} \%$ fr. wt.) as citrine needles (EtOAc-PE); mp 191-192 ${ }^{\circ} \mathrm{C}$ (lit. ${ }^{22} 191-194{ }^{\circ} \mathrm{C}$ ); TLC: $\mathrm{R}_{f} 0.35$; $[\mathrm{a}]_{\mathrm{D}}{ }^{12.5}+7.8\left(\mathrm{MeOH} ; c\right.$ 0.5) (lit. ${ }^{22}[\alpha]_{\mathrm{D}}^{30.5}+7.0\left[\mathrm{MeOH} ; c\right.$ 1.0]); IR $v \mathrm{D}(\mathrm{KBr}) \mathrm{cm}^{-1}: 3505,1640$, 
1590; UV-Vis $\lambda(\mathrm{EtOH}) \mathrm{nm}(\log \varepsilon)$ : 228 (4.52), 270 (4.77), 320 (4.11), 400 (4.00); ${ }^{1} \mathrm{H}$ NMR $\left(\mathrm{CDCl}_{3}\right) \delta 1.46$ (3H, s, 3-Me), 2.84 (2H, m, H-2), 3.05 (2H, m, H-4), 3.89 (3H, s, 6-OMe), 6.49 $(1 \mathrm{H}, \mathrm{d}, J=2.2, \mathrm{H}-7), 6.55$ (1H, d, $J=2.2, \mathrm{H}-5), 6.87$ (1H, s, H-10), 9.80 (1H, s, 8-OH), 16.11 (1H, s, 9-OH); EIMS m/z (rel. int.): 288 (M+1 100), 270 (30), 246 (10), 230 (25), 43 (20); (S)atrochrysone 8 (2.6 mg, $2.2 \times 10^{-2} \%$ fr. wt.) as green-yellow needles $\left(\mathrm{CHCl}_{3}-\mathrm{PE}\right)$; mp 232-236 ${ }^{\circ} \mathrm{C}$ (decomp.) (lit. ${ }^{22} 234-238{ }^{\circ} \mathrm{C}$ [decomp.]); TLC: $R f$ 0.24; $[\alpha]^{30.5}+6.5$ (MeOH; c 0.8) (lit.. $[\alpha]_{546}^{25}+8.2\left[\mathrm{MeOH} ; c\right.$ 0.2]); IR $v(\mathrm{KBr}) \mathrm{cm}^{-1}: 3460,1642,1600 ; \mathrm{UV}-\mathrm{Vis} \lambda(\mathrm{EtOH}) \mathrm{nm}(\log$ $\varepsilon$ ): 227 (3.25), 272 (3.60), 320 (2.75), 333 sh (2.63), 398 (3.03); ${ }^{1} \mathrm{H}$ NMR (d $d_{6}$-acetone) $\delta 1.40$ (3H, s, 3-Me), 2.77 (1H, dd, $J=1.95$ and 17.3, H-2), 2.90 (1H, d, $\left.J=17.3, \mathrm{H}_{\mathrm{ax}}-2\right), 3.00$ (1H, br d, $\left.J=16.1, \mathrm{H}_{\mathrm{eq}}-4\right), 3.08\left(1 \mathrm{H}, \mathrm{d}, J=16.1, \mathrm{H}_{\mathrm{ax}}-4\right), 4.03(1 \mathrm{H}, \mathrm{s}, 3-\mathrm{OH}), 6.38(1 \mathrm{H}, \mathrm{d}, J=2.2, \mathrm{H}-7)$, 6.58 (1H, d, $J=2.2, \mathrm{H}-5), 6.84$ (1H, s, H-10), 9.20 (1H, s, 6-OH), 9.84 (1H, s, 8-OH), $16.52(1 \mathrm{H}$, s, 9-OH); EIMS m/z (rel. int.): 274 ( $\left.\mathrm{M}^{+}, 100\right), 256$ (80), 232 (12), 216 (32), 43 (22); emodin 1-Omethyl ether 11 (0.4 mg, $3.3 \times 10^{-3} \%$ fr. wt.) as orange needles (EtOAc-PE); mp 265-267 ${ }^{\circ} \mathrm{C}$ (lit. ${ }^{25}$ 262-265 ${ }^{\circ} \mathrm{C}$ ); TLC: $R f$ 0.48; HR EIMS m/z (rel. int.) found 284.0590 [M+] (100\%), $\mathrm{C}_{16} \mathrm{H}_{12} \mathrm{O}_{5}$ requires 284.0686; IR $v(\mathrm{KBr}) \mathrm{cm}^{-1}$ : 3400, 1665, 1625, 1590; UV-Vis $\lambda(\mathrm{EtOH}) \mathrm{nm}$ (log $\varepsilon$ ): 216 (4.68), 249 (4.34), 267 sh (4.30), 282 (4.41), 429 (3.84); ${ }^{1} \mathrm{H}$ NMR $\left(\mathrm{CDCl}_{3}\right) \delta 2.51$ (3H, s, 3-Me), 4.06 (3H, s, 1-OMe), 6.67 (1H, d, $J=2.45, \mathrm{H}-5), 7.16$ (1H, br s, H-2), 7.21 (1H, d, $J=2.45, \mathrm{H}-7), 7.77$ (1H, br s, H-4), 13.27 (1H, s, 8OH); EIMS m/z (rel. int.): 284 (M+, 100), 266 (39), 255 (25), 238 (69); emodin 10 (1.0 mg, 8.3 x 10 $0^{-3} \%$ fr. wt.) as orange needles (EtOAc); mp 257-258 ${ }^{\circ} \mathrm{C}$; TLC: Rf 0.65; IR $v(\mathrm{KBr}) \mathrm{cm}^{-1}$ : 3448, 1660, 1628; UV-Vis $\lambda(\mathrm{EtOH}) \mathrm{nm}(\log$ $\varepsilon$ ): 218 (4.64), 250 (4.24), 262 (4.20), 287 (4.36), 436 (3.98); ${ }^{1} \mathrm{H}$ NMR $\left(\mathrm{CDCl}_{3}\right) \delta 2.47$ (3H, s, 3Me), 6.67 (1H, d, $J=2.45, \mathrm{H}-5), 7.15$ (1H, br s, H-2), 7.26 (1H, d, $J=2.45, \mathrm{H}-7), 7.58$ (1H, br s, $\mathrm{H}-4), 12.08$ and 12.20 (2H, s, 1/8-OH); EIMS m/z (rel. int.): 270 (M+, 100); and emodin anthrone 13 (0.5 mg, $4.2 \times 10^{-3} \%$ fr. wt.) as yellow-green plates (CHCl3); mp 250-254 ${ }^{\circ} \mathrm{C}$ (decomp.) (lit. ${ }^{27} 250-258{ }^{\circ} \mathrm{C}$ [decomp.]); TLC: Rf 0.42; HR EIMS m/z (rel. int.) found 256.0701 $[\mathrm{M}+]$ (100\%), $\mathrm{C}_{16} \mathrm{H}_{12} \mathrm{O}_{5}$ requires 256.0740; IR $v(\mathrm{KBr}) \mathrm{cm}^{-1}: 3400,1622,1599,1559$; UV-Vis $\lambda$ $(\mathrm{EtOH}) \mathrm{nm}(\log \varepsilon)$ : 258 (4.00), 268 (4.02), 302 (3.93), 360 (4.14); ${ }^{1} \mathrm{H}$ NMR ( $d_{6}$-acetone) $\delta 2.59$ (3H, s, 3-Me), 4.31 (2H, s, H-10), 5.92 (1H, d, $J=2.00, \mathrm{H}-5), 6.15$ (1H, br s, H-2), 6.20 (1H, d, $J$ = 2.00, H-7), 6.42 (1H, br s, H-4), 12.21 and 12.40 (2H, s, 1/8-OH); FAB MS m/z (rel. int.): 279 ([M+Na $\left.]^{+}, 45\right), 257\left([\mathrm{M}+1]^{+}, 12\right), 237$ (100); EIMS m/z (rel. int.): 256 ( $\left.\mathrm{M}^{+}, 100\right), 241$ (17), 228 (13), 213 (18).

\section{Acknowledgements}

We are grateful to the Australian Research Council for financial support and to Professors D. W. Cameron, for provision of a synthetic sample of emodin 1-O-methyl ether, and W. Steglich, for samples of natural flavommanins. P. M. M. is the recipient of a Melbourne University Postgraduate Research Scholarship. We are thankful to the Departments of Chemistry and Plant and Microbial Sciences at the University of Canterbury, Christchurch, New Zealand for 
hospitality and facilities to collect and extract New Zealand species. Dr Roy Watling, Edinburgh, is acknowledged for help and encouragement (over many years) and, in the present case, for lodging herbarium specimens and crucial help with taxonomy.

\section{References and Notes}

1. Part 67 In the series Pigments of Fungi. For Part 66, see Gill, M.; Saubern, S.; Yu, J. Aust. J. Chem. 2000 , 53 , 213.

2. This paper is dedicated to Professor D. W. Cameron to mark his retirement as Professor of Organic Chemistry from the University of Melbourne and in recognition of his outstanding contributions to the structural elucidation and synthesis of naturally occurring quinones.

3. Gill, M. Aust. J. Chem. 1995, 48, 1.

4. Gill, M. Nat. Prod. Rep. 1994, 11, 67; Nat. Prod. Rep. 1996 , 13, 513; Nat. Prod. Rep. 1999, 16, 301.

5. Gill, M.; Gimenez, A.; Watling, R. J. Nat. Prod. 1992 , 55, 372.

6. See for example: Gill, M.; Gimenez, A.; Jhingran, A. G.; Milanovic, N. M; Palfreyman, A. R. J. Chem. Soc., Perkin Trans. 1 1998, 3431; and references cited therein.

7. Gill, M.; Steglich, W. In Progress in the Chemistry of Organic Natural Products; Springer, Vienna 1987, Vol. 51, pp 1-317.

8. The code refers to the accession number under which voucher specimens are held in the herbarium of the Royal Botanic Garden, Edinburgh.

9. Gill, M.; Qureshi, A; Watling, R. J. Nat. Prod. 1992, 55, 517.

10. Gill, M.; Morgan, P. M. J. Nat. Prod. 1999, 62, 1298.

11. Thomson, R. H. In Naturally Occurring Quinones, $2^{\text {nd }}$ Ed.; Academic Press: London, 1971.

12. Gill, M.; Gimenez, A. J. Chem. Soc., Perkin Trans. 1 1995, 645.

13. Thomson, R. H. In Naturally Occurring Quinones IV, Recent Advances; Blackie: London, 1997.

14. Thomson, R. H. In Naturally Occurring Quinones III, Recent Advances; Chapman and Hall: London, 1987.

15. Savard, J.; Brassard, P. Tetrahedron 1984 , 40, 3455.

16. Gill, M.; Gimenez, A.; Jhingran, A. G.; Palfreyman, A. R. Tetrahedron: Asymmetry 1990 , 1, 621.

17. Billen, G.; Karl, U.; Scholl, K. D.; Stroech, K. D; Steglich, W. In Natural Products Chemistry III; Springer: Berlin, Atta-ut-Rahman, Le Quesne, P. W. Eds.; 1988, pp 305-315.

18. Oertel, B., Dissertation, University of Bonn, 1984.

19. Cornforth, J. W. Aust. J. Chem. 1993 , 46, 157.

20. Steglich, W.; Reininger, W. Chem. Ber. 1972, 105, 2922.

21. Keller, G.; Ammirati, J. F. Mycotaxon 1983, 18, 357. 
22. Gill, M.; Gimenez, A.; Jhingran, A. G.; Smrdel, A. F. Phytochemistry 1989, $28,2647$.

23. Ayer, W. A.; Trifonov, L. S. J. Nat. Prod. 1994, 57, 317.

24. Shu, Y. -Z; Arcuri, M.; Koslowski, M. R.; Wang, R. R.; Lam, K. S.; Chang, L. -P.; Pernik, D. J. Antibiotics 1994, 47, 1328.

25. Cameron, D. W.; Crossley, M. J. Aust. J. Chem. 1977, 30, 1161.

26. Banville, J.; Brassard, P. J. Chem. Soc., Perkin Trans. 1 1976, 1852.

27. (a) Lobadie, R. P.Pharm. Weekblad. 1970, 105, 189 (b) Lobadie, R. P.; Otten, J.;Svendsen, A. B. Pharm. Weekblad. 1972, 107, 541. 